\title{
JNVESTJGAACJÓN
}

\section{Sensory and chemical stability in coated peanuts with the addition of essential oils and synthetic antioxidants}

\author{
By R.H. Olmedo', V. Nepote ${ }^{2}$ and N.R. Grosso ${ }^{1 *}$
}

\author{
Química Biológica, Facultad de Ciencias Agropecuarias (UNC), IMBIV-CONICET, Av. Valparaíso s/n, CC \\ 509, (5016) Córdoba, Argentina.

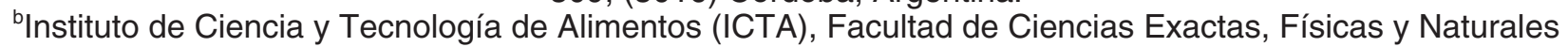 \\ (UNC), IMBIV-CONICET, Av. Vélez Sarsfield 1611, (5016) Córdoba, Argentina. \\ *Corresponding author: nrgrosso@agro.unc.edu.ar
}

\section{RESUMEN}

Estabilidad química y sensorial de maní cubiertos con el agregado de aceites esenciales y antioxidantes sintéticos

El objetivo de este trabajo fue evaluar el efecto antioxidante de aceites esenciales sobre la estabilidad oxidativa en maní recubiertos. Se prepararon maníes recubiertos sin agregados (CP), y con el agregado de aceites esenciales de romero $(\mathrm{CP}-\mathrm{R})$, orégano (CP-O) y laurel (CP-L) y BHT (CP$\mathrm{BHT})$. Se midieron, durante 112 días de almacenamiento, los valores de peróxidos (PV) y p-anisidina (AV), y las intensidades de atributos sensoriales mediante análisis descriptivo. $\mathrm{CP}-\mathrm{BHT}$ presentó el menor valor de PV y AV. CP-R, CP-O y CP-L tuvieron mayor PV y AV respecto a CP. Los valores de intensidad del sabor oxidado y cartón tuvieron un mayor incremento en CP durante el almacenamiento con respecto a los otros productos estudiados. La muestra CP-BHT también mostró los menores valores de intensidad de estos atributos sensoriales. Los aceites esenciales de laurel, orégano y romero presentaron actividad antioxidante e incrementaron la vida útil del maní recubierto.

PALABRAS CLAVE: Arachis hypogaea - Laurel - Orégano - Romero - Vida útil.

\section{SUMMARY}

Sensory and chemical stability in coated peanuts with the addition of essential oils and synthetic antioxidants

The objective of this work was to evaluate the antioxidant effect of essential oils on the oxidative stability of coated peanuts. Untreated coated peanuts $(\mathrm{CP})$ and treated coated peanuts with the addition of rosemary $(\mathrm{CP}-\mathrm{R})$, oregano (CP-O) and laurel (CP-L) essential oils and BHT (CP$\mathrm{BHT})$ were prepared. Peroxide values (PV) and $p$-anisidine values (AV) and the intensity ratings of sensory attributes by descriptive analysis were measured during 112 days of storage at room temperature $\left(23^{\circ} \mathrm{C}\right)$. CP-BHT exhibited the lowest PV and AV increase. CP-R, CP-O and CP-L showed lower rates of increase in PV and AV than CP. The oxidized and cardboard flavor intensity ratings increased much more in CP during storage than the other studied products. CP$\mathrm{BHT}$ also showed the lowest increase in the intensity ratings of these sensory attributes. Three essential oils, namely, laurel, oregano and rosemary showed antioxidant activity and increased the shelf life of coated peanuts.

KEY-WORDS: Arachis hypogaea - Laurel - Oregano Rosemary-Shelf-life.

\section{INTRODUCTION}

Peanuts (Arachis hypogaea L.) contain approximately $47-53 \%$ oil. About $80 \%$ of peanut oil is composed of $30-35 \%$ linoleic and $45-50 \%$ oleic acids (Grosso and Guzman, 1995; Grosso et al., 1997 and 1999). This fatty acid composition is susceptible to developing rancidity and subsequent off-flavors through the lipid oxidation process (Frankel, 2005). The oxidation products show harmful effects for human health such as heart disease, emphysema, mutagenesis and carcinogenesis (Benzie, 1996).

Synthetic antioxidants, such as butylated hydroxyanisole (BHA), butylated hydroxytoluene $(\mathrm{BHT})$ and propyl gallate (PG), are used in many foods to prevent rancidity. However, their safety for human health is questionable (Pokorny, 1991). For these reasons, the interest in using naturally occurring antioxidants such as essential oils from aromatic plants has increased. Natural antioxidants are presumed to be safe because they occur in nature and in many cases are derived from plant sources (Frankel, 2005).

Edible coatings in food products may prevent moisture loss and oxygen diffusion, and may be used as a vehicle for additives such as antioxidants. At the same time, edible coatings could be used for increasing the shelf life of food products and improving the stability in lipid-containing foods, thus preventing a loss in sensory and nutritional quality. Different coated peanut products have been developed with the objective of improving their shelf life (Mestrallet et al., 2004; Nepote et al., 2008). Essential oils from aromatic plants could be included in coated peanuts as natural antioxidants. 
These essential oils could also be used as a flavor for improving consumer acceptance. Acceptability in peanut products decreases when the oxidation process occurs during storage with increasing values of chemical and sensory indicators of lipid oxidation (Grosso and Resurreccion, 2002; Nepote et al., 2006a, b, c). Quality preservation during storage is a serious matter for the food industry and therefore, the use of essential oils as natural antioxidants is an alternative. Coated peanuts like cracker coated peanuts are a peanut product that has a shelf life of between 60 to 120 days in commercial brands from Argentina. The end of the shelf life in this product is characterized by high peroxide value and the detection of off-flavors because of the peanut lipid oxidation. This shelf life is not long enough for the logistics of the distribution around the country or the word.

Essential oils from aromatic species such as oregano, rosemary and laurel showed antioxidant properties (Kulisic et al., 2004; Olmedo et al., 2008). However, their antioxidant effects analyzed in food has not been studied in depth. The objective of this work was to evaluate the antioxidant effect of essential oils on the oxidative stability of coated peanuts by analyzing chemical and sensory changes during storage.

\section{MATERIALS AND METHODS}

\subsection{Materials}

Sound, mature seeds of the peanut type Runner, size 38/42 kernels per oz (crop 2008) were provided by the company, Lorenzati, Ruescht y Cia, Ticino, Córdoba, Argentina. Before processing, peanuts were inspected and damaged or bruised kernels were removed manually.

In this work, three aromatic species were used: oregano (Origanum vulgare), rosemary (Rosmarinus officinalis) and laurel (Laurus nobilis). Leaves of each species (crop 2009) were provided by the "Facultad de Ciencias Agropecuarias - Universidad Nacional de Córdoba", Córdoba, Argentina. The essential oils were obtained by hydrodistillation according to Zygadlo et al. (1995). The extracted essential oils were then kept in dark glass flasks at $-18^{\circ} \mathrm{C}$ until they were used.

\subsection{Product Elaboration}

Coated Peanuts (CP). The coated peanuts were prepared using 50\% raw peanuts, $20 \%$ syrup solution and $30 \%$ flour blend. The syrup solution was composed of $55 \%$ distilled water, $35 \%$ sugar (La Fronterita, Famailla, Tucuman, Argentina), 10\% hydrolyzed starch (Star-Dry, National Starch, USA) and $4 \%$ salt (Celusal, General San Martin, La Pampa, Argentina). The flour blend was prepared with $60 \%$ wheat flour (Graciela Real, Cordoba, Argentina), $30 \%$ modified starch (National 5730, National Starch, USA) and 10\% corn starch (Maicena, Buenos Aires,
Argentina). The coating procedure was performed using a coating pan rotating at $28 \mathrm{rpm}$ for 5 minutes. The coated peanuts were roasted in the oven at 165 ${ }^{\circ} \mathrm{C}$ for $45 \mathrm{~min}$ (Grosso et al., 2008).

Coated Peanuts with Essential Oils and BHT. The coating procedure was the same as described above. On coated peanuts, $0.005 \% \mathrm{w} / \mathrm{w}$ of essential oil or synthetic antioxidant butyl hydroxyl toluene (BHT) was added. The essential oil or BHT was dissolved in $20 \mathrm{~mL}$ of ethanol (Porta, Cordoba, Argentina) and added superficially to $1 \mathrm{~kg}$ of coated peanuts. The following treatments were prepared: coated peanuts with BHT (CP-BHT) and coated peanuts with the essential oils of oregano (CP-O), laurel (CP-L) and rosemary (CP-R).

\subsection{Storage Conditions and Samplings}

After preparation, samples were placed in $27 \times$ $28 \mathrm{~cm}$ plastic bags (Ziploc, Johnson \& Son, Buenos Aires, Argentina). The samples were stored at $23^{\circ} \mathrm{C}$ (room temperature). Samples from each product were removed from storage to evaluate chemical and sensory indicators of lipid oxidation (Nepote et al., 2009). Samples were taken at 28, 56, 84 and 112 days. Samples were also evaluated on day "zero". This storage time was chosen because this kind of peanut product, "cracker coated peanuts", has a shelf life of less than 120 days for commercial brands in Argentina. Therefore, it is possible to draw conclusions about the addition of essential oils and their effect as natural antioxidants in the shelf life of the product during this storage period.

\subsection{Chemical analyses}

Peanut oil extraction. The oil was obtained by cold pressing using a 20 ton press per $\mathrm{cm}^{2}$ for a pressing time of 10 min (Manual, HE-DU, Hermes I. Dupraz SRL, Córdoba, Argentina). The obtained peanut oil was used for chemical analyses: peroxide and $p$-anisidine measurements.

Peroxide value (PV). PV was determined according to the AOAC method 28.022 (AOAC, 1980). The PV was expressed as miliequivalents of active oxygen per kilogram of oil $\left(\mathrm{meqO}_{2} / \mathrm{kg}\right)$.

p-Anisidine value (AV). AV was evaluated following the IUPAC method (IUPAC, 1987). The $p$-anisidine value was given by the formula: $\mathrm{AV}=$ $25 x(1.2 A s-A b) \times\left(\mathrm{m}^{-1}\right)$, where "As" is absorbance of the fat solution after reaction with the $p$-anisidine reagent, "Ab" is the absorbance of the fat solution and " $\mathrm{m}$ " is the mass of peanut oil in grams.

Totox value (TV). Totox value was calculated using the $\mathrm{PV}$ and $\mathrm{AV}$ results according to the formula: Totox value $=2 \mathrm{PV}+\mathrm{AV}$.

\subsection{Sensory analysis}

Descriptive analysis. A total of 12 trained panellists (9 female and 3 male) participated in the 
descriptive analysis of the coated peanut storage study. All panellists had 4 years of experience evaluating peanut products (roasted peanuts, honey roasted peanuts and fried-salted peanuts) and were selected on the following criteria: a) people with natural dentition, b) people without food allergies, c) non-smokers, d) people between the ages of $18-64$, e) people who consume roasted peanuts and/or peanut products at least once a month, f) people available for all sessions, g) people interested in participating, and h) people able to verbally communicate their observations regarding the product (Plemmons and Resurreccion, 1998). Before being qualified, all panellists showed a perfect score in a taste sensitivity test and the ability to identify 5 of 7 commonly found food flavors (Meilgaard et al., 1991).

All 12 panellists were trained and calibrated in 4 training sessions over 4 days. Each training session lasted 2 hours. Descriptive analysis procedures as described by Meilgaard et al. (1991) and Grosso and Resurreccion (2002) were used during the training and evaluation sections. Panellists evaluated samples using a "hybrid" descriptive analysis method consisting of the Quantitative Descriptive Analysis (Tragon Corp., Redwood City, Calif., U.S.A.) and the Spectrum ${ }^{\mathrm{TM}}$ Analysis Methods (Sensory Spectrum, Inc., Chatham, N.J., U.S.A.). A $150 \mathrm{~mm}$ unstructured line scale was used (Plemmons and Resurreccion, 1998). A list of attribute definitions (Table 1) and a sheet with warm-up and reference intensity ratings for each attribute were developed during the training sessions (Grosso and Resurreccion, 2002). The attribute definitions were based on a peanut lexicon (Meilgaard et al., 1991).

Sample evaluation. All samples were evaluated in partitioned booths under fluorescent light at room temperature. Ten grams of the product sample were placed into plastic cups with lids coded with 3 digit random numbers. Panellists evaluated 7 or 8 samples per day plus a warm-up sample. The final lists of warm-up and reference intensity ratings and definitions were posted in the booths for all test sessions. Samples were tested using a complete randomized block design. The data were registered on paper ballots.

\subsection{Statistical analysis}

The experiment was performed in three repetitions. The data were analyzed using the InfoStat software, version 1.1 (Facultad de Ciencias Agropecuarias, Universidad Nacional de Córdoba). Means and standard deviations were calculated. Analysis of variance and Duncan tests were used to detect significant differences ( $a=0.05$ ) between means. The Pearson coefficient was used to calculate the correlation between dependent variables from chemical and sensory analyses. Regression equations were used to determine if the independent variables (time) had an effect on the sensory attributes, Peroxide value and P-anisidine value (Sokal and Rohlf, 1994).

\section{RESULT AND DISCUSSION}

\subsection{Chemical and sensory analyses in coated peanuts from storage}

Chemical analysis. Figure 1 presents the changes in chemical indicators of lipid oxidation (PV and AV) in treated and untreated coated peanut samples during storage for 112 days at room temperature. The chemical indicators of lipid oxidation increased with storage time in all coated peanut samples. A similar trend was observed in a previous work that studied fried-salted peanuts prepared with Runner peanuts (Nepote et al., 2006c).

Significant differences in PV were observed among the peanut products. CP-BHT had lower PV $\left(17.69 \mathrm{~m} \mathrm{eq}_{2} / \mathrm{kg}\right.$ ) than the other samples from day 28. The increase in PV was lower in CP-O, CP-L and CP-R from day 56 of storage than in untreated $\mathrm{CP}$. The results among coated peanuts added with essential oils did not show significant differences.

Significant differences in AV were detected among the samples. CP-BHT also exhibited the lowest $\mathrm{AV}$ in comparison with untreated $\mathrm{CP}$. The coated peanuts with essential oils (CP-O, CP-L and
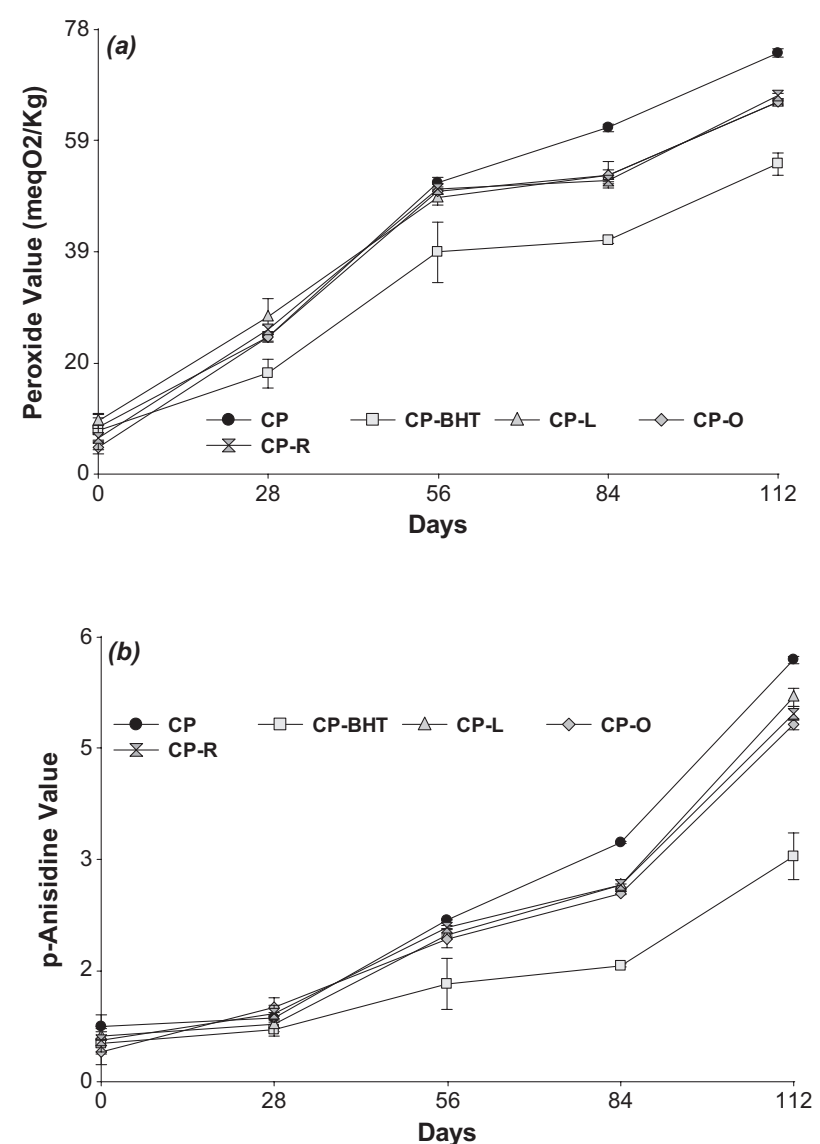

Figure 1

Results of chemical analysis: a) peroxide value (PV) and b) $p$-anisidine value (AV) in coated peanuts (CP), coated peanuts with addition of essential oils of oregano (CP-O), rosemary $(\mathrm{CP}-\mathrm{R})$ and laurel $(\mathrm{CP}-\mathrm{L})$ and $\mathrm{BHT}(\mathrm{CP}-\mathrm{BHT})$ during storage 
Table 1

Definitions of attributes, standard references and warm-up intensity ratings used in descriptive analysis of coated peanuts with or without addition of oregano, laurel and rosemary essential oils and BHT

\begin{tabular}{|c|c|c|c|c|c|}
\hline Attribute $^{a}$ & Definition $^{b}$ & Reference & $\begin{array}{l}\text { Reference } \\
\text { intensity }^{c}\end{array}$ & $\begin{array}{l}\text { Warm-up } \\
\text { intensity }^{\mathrm{c}, \mathrm{d}}\end{array}$ & $\begin{array}{l}\text { Samples } \\
\text { intensity }^{\mathrm{c}, \mathrm{e}}\end{array}$ \\
\hline \multicolumn{6}{|l|}{ Appearance } \\
\hline 1- Brown Color & $\begin{array}{l}\text { The intensity or the strength } \\
\text { of brown color from light } \\
\text { to dark brown. }\end{array}$ & $\begin{array}{l}\text { Cardboard (lightness } \\
\text { value, } L=47 \pm 1.0 \text { ) }\end{array}$ & 65 & 44 & $47.6 \pm 1.4$ \\
\hline 2- Roughness & $\begin{array}{l}\text { The appearance associated } \\
\text { with an uneven surface. }\end{array}$ & Corn flakes ${ }^{f}$ & 85 & 23 & $32.5 \pm 1.1$ \\
\hline 3- Glossiness & $\begin{array}{l}\text { The appearance associated } \\
\text { with the amount of light } \\
\text { reflected by the product } \\
\text { surface. }\end{array}$ & $\begin{array}{l}\text { Peanuts coated with } \\
\text { chocolate }^{g}\end{array}$ & 58 & 21 & $17.6 \pm 0.7$ \\
\hline \multicolumn{6}{|l|}{ Aromatics } \\
\hline \multirow[t]{3}{*}{$\begin{array}{l}\text { 4- Essential Oil } \\
\text { Aroma }\end{array}$} & $\begin{array}{l}\text { The aroma associated with the } \\
\text { essential oils of rosemary, }\end{array}$ & $\begin{array}{l}0.1 \% \text { rosemary essential } \\
\text { oil in sunflower oil }\end{array}$ & 42 & 0 & $22.1 \pm 1.1$ \\
\hline & oregano and laurel. & $\begin{array}{l}0.1 \% \text { oregano essential } \\
\text { oil in sunflower oil }{ }^{\mathrm{h}}\end{array}$ & 64 & 0 & $27.0 \pm 1.2$ \\
\hline & & $\begin{array}{l}0.1 \% \text { laurel essential oil } \\
\text { in sunflower oil }{ }^{\mathrm{h}}\end{array}$ & 53 & 0 & $23.6 \pm 0.9$ \\
\hline 5- Roasted Peanutty & $\begin{array}{l}\text { The aroma associated with } \\
\text { medium roasted peanuts. }\end{array}$ & Dry roasted peanuts ${ }^{i}$ & 76 & 74 & $52.6 \pm 1.1$ \\
\hline 6- Oxidized & $\begin{array}{l}\text { The aroma associated with } \\
\text { rancid fats and oils. }\end{array}$ & Rancid peanuts $^{j}$ & 75 & 5 & $6.1 \pm 0.5$ \\
\hline 7- Cardboard & $\begin{array}{l}\text { The aroma associated with } \\
\text { wet cardboard. }\end{array}$ & Moist cardboard ${ }^{k}$ & 58 & 12 & $10.2 \pm 0.8$ \\
\hline \multicolumn{6}{|c|}{ 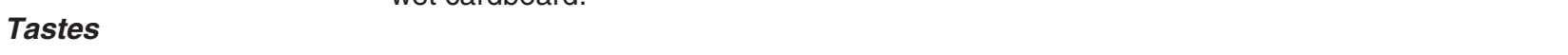 } \\
\hline 8- Sweetness & $\begin{array}{l}\text { Taste on the tongue } \\
\text { associated with sucrose } \\
\text { solutions. }\end{array}$ & $\begin{array}{l}2.0 \% \text { sucrose solution } \\
5.0 \% \text { sucrose solution } \\
10.0 \% \text { sucrose solution }\end{array}$ & $\begin{array}{c}20 \\
50 \\
100\end{array}$ & 19 & $26.1 \pm 3.5$ \\
\hline 9- Salty & $\begin{array}{l}\text { Taste on the tongue } \\
\text { associated with sodium } \\
\text { chloride solutions. }\end{array}$ & $\begin{array}{c}0.2 \% \mathrm{NaCl} \text { solution } \\
0.35 \% \mathrm{NaCl} \text { solution } \\
0.5 \% \mathrm{NaCl} \text { solution }\end{array}$ & $\begin{array}{l}25 \\
50 \\
85\end{array}$ & 9 & $16.4 \pm 0.9$ \\
\hline 10- Sourness & $\begin{array}{l}\text { Taste on the tongue } \\
\text { associated with acid agents } \\
\text { such as citric acid solutions. }\end{array}$ & $\begin{array}{l}0.05 \% \text { citric acid solution } \\
0.08 \% \text { citric acid solution } \\
0.15 \% \text { citric acid solution }\end{array}$ & $\begin{array}{c}20 \\
50 \\
100\end{array}$ & 5 & $5.9 \pm 0.6$ \\
\hline 11- Bitterness & $\begin{array}{c}\text { Taste on the tongue } \\
\text { associated with bitter solutions } \\
\text { such as caffeine. }\end{array}$ & $\begin{array}{l}0.05 \% \text { caffeine solution } \\
0.08 \% \text { caffeine solution } \\
0.15 \% \text { caffeine solution }\end{array}$ & $\begin{array}{c}20 \\
50 \\
100\end{array}$ & 7 & $8.2 \pm 1.1$ \\
\hline \multicolumn{6}{|l|}{ Feeling Factors } \\
\hline 12- Astringency & $\begin{array}{c}\text { The shrinking or puckering of } \\
\text { the tongue surface }\end{array}$ & Tea infusion ' & 45 & 9 & $9.2 \pm 0.5$ \\
\hline \multicolumn{6}{|l|}{ Texture } \\
\hline 13- Hardness & $\begin{array}{l}\text { Force needed to compress a } \\
\text { food between molar teeth. }\end{array}$ & Almonds ${ }^{m}$ & 74 & 48 & $50.8 \pm 1.3$ \\
\hline 14- Crunchiness & $\begin{array}{l}\text { Force needed and amount of } \\
\text { sound generated from chewing } \\
\text { a sample with molar teeth. }\end{array}$ & Corn flakes $^{f}$ & 90 & 41 & $71.2 \pm 2.7$ \\
\hline
\end{tabular}

\footnotetext{
attributes listed in order as perceived by panellists; ${ }^{\mathrm{b}}$ The attribute definitions were based on a lexicon for peanut samples (Jonhnsen et al., 1988 Meilgaard et al., 1991); ' Intensity ratings are based on $150 \mathrm{~mm}$ unstructured line scales; ${ }^{\mathrm{d}}$ Medium roasted peanuts (lightness value, $\mathrm{L}=50 \pm 1$ ), Type Runner, Blanched, Cordoba, Argentina; ${ }^{\mathrm{e}}$ The mean intensity rating measured on day "0" of storage from peanut products.; ${ }^{\dagger}$ Corn flakes, Granix, Buenos Aires, Argentina; ${ }^{9}$ Peanuts coated with chocolate, ARCOR, Colonia Caroya, Córdoba, Argentina; ${ }^{\mathrm{h}}$ Refined sunflower oil (Natura, AGD, General Cabrera, Argentina); ' Dry roasted peanuts, type Runner, JL SA, Ticino, Córdoba, Argentina.

Dry roasted peanuts (type Runner, blanched, Córdoba, Argentina) stored at $40^{\circ} \mathrm{C}$ for 120 days (intensity rating $=30$ ) and 6 months (intensity rating $=112) ;{ }^{k}$ Moist cardboard: $1 \mathrm{~mL}$ distilled water absorbed by $0.5 \mathrm{~g}$ cardboard

'Tea infusion: 4 tea bags (La Virginia, Córdoba, Argentina) soaked in 1 liter of distilled water at $80^{\circ} \mathrm{C}$ for 10 minutes.; ${ }^{\mathrm{m}}$ Almonds, Grandiet, Córdoba, Argentina.
} 
CP-R) showed a small increase in AV with respect to $\mathrm{CP}$, also observed from day 56 of storage. The results of this research showed similar behavior in the antioxidant properties of these three essential oils to the results reported in a study performed on friedsalted peanuts (Olmedo et al., 2008). However, the antioxidant effect of essential oils was less marked in this study. Kulisic et al. (2004) also detected antioxidant activity in oregano essence oil measured by the DPPH and TBAR methods. Rosemary extract was effective against lipid oxidation in bread sprayed with different vegetable oils (Frutos and HernandezHerrero, 2005). The antioxidant property of these essential oils could be due to the presence of phenolic compounds in their composition with high radical scavenging activity. Compounds like thymol, eugenol and camphor were found in oregano, laurel and rosemary, respectively. These compounds have shown a high antioxidant activity in another study (Sacchetti et al., 2005). Other polyphenolic compounds obtained from peanut skins have also shown antioxidant activity and these compounds could also be used as natural antioxidants in food products (Nepote et al., 2002).

Significant differences in TV were observed among the peanut products (Table 2). CP-BHT had the lowest TV after day 28 of storage. The increase in TV was significantly lower in CP-O, CP-L and

Table 2

TOTOX values in coated peanuts (CP), coated peanuts with addition of essential oils of oregano (CP-O), rosemary (CP-R) and laurel (CP-L) and $\mathrm{BHT}(\mathrm{CP}-\mathrm{BHT})$ during storage time

\begin{tabular}{|c|c|c|c|}
\hline \multirow{2}{*}{ Day } & \multirow{2}{*}{ Samples $^{a}$} & \multicolumn{2}{|c|}{ тотох Value } \\
\hline & & Mean - Standard deviation & ANOVA $^{\mathrm{b}}$ \\
\hline \multirow{5}{*}{0} & $\mathrm{CP}$ & $17.6 \pm 4.69$ & $b$ \\
\hline & $\mathrm{CP}-\mathrm{BHT}$ & $16.36 \pm 4.39$ & $a b$ \\
\hline & CP-L & $19.64 \pm 2.79$ & $\mathrm{~b}$ \\
\hline & CP-O & $10.01 \pm 2.4$ & a \\
\hline & CP-R & $13.78 \pm 4.57$ & $a b$ \\
\hline \multirow{5}{*}{28} & $\mathrm{CP}$ & $49.45 \pm 1.52$ & $b$ \\
\hline & CP-BHT & $36.44 \pm 5.06$ & a \\
\hline & CP-L & $56.63 \pm 6.33$ & c \\
\hline & CP-O & $49.73 \pm 1.74$ & $\mathrm{bc}$ \\
\hline & CP-R & $52.24 \pm 1.55$ & bc \\
\hline \multirow{5}{*}{56} & $\mathrm{CP}$ & $105.24 \pm 1.53$ & $b$ \\
\hline & CP-BHT & $79.84 \pm 10.35$ & a \\
\hline & CP-L & $99.62 \pm 2.73$ & $b$ \\
\hline & CP-O & $101.74 \pm 0.57$ & $\mathrm{~b}$ \\
\hline & CP-R & $102.83 \pm 1.83$ & $\mathrm{~b}$ \\
\hline \multirow{5}{*}{84} & $\mathrm{CP}$ & $125.4 \pm 1.28$ & c \\
\hline & CP-BHT & $84.15 \pm 1.14$ & a \\
\hline & CP-L & $107.97 \pm 2.02$ & $\mathrm{~b}$ \\
\hline & CP-O & $108.21 \pm 4.74$ & $\mathrm{~b}$ \\
\hline & CP-R & $106.26 \pm 1.36$ & $\mathrm{~b}$ \\
\hline \multirow{5}{*}{112} & $\mathrm{CP}$ & $154.21 \pm 1.35$ & $\mathrm{C}$ \\
\hline & CP-BHT & $112.5 \pm 3.72$ & a \\
\hline & CP-L & $136.55 \pm 0.58$ & $\mathrm{~b}$ \\
\hline & CP-O & $136.25 \pm 0.99$ & $b$ \\
\hline & CP-R & $138.42 \pm 1.06$ & $\mathrm{~b}$ \\
\hline
\end{tabular}

${ }^{a} \mathrm{CP}$ : coated peanuts, CP-BHT: coated peanuts with $\mathrm{BHT}$, CP-O: coated peanuts with oregano essential oil, CP-R: coated peanuts with rosemary essential oil and CP-L: coated peanuts with laurel essential oil. ${ }^{b}$ The same letters in the column for every storage day means that are not significantly different among treatments at $\alpha=0.05$. 
CP-R from day 84 of storage than in untreated $\mathrm{CP}$. There were no significant differences in TV among coated peanuts with the addition of essential oils after day 56 of storage.

\subsection{Descriptive Analysis}

The intensity ratings for 15 sensory attributes of coated peanuts using a descriptive analysis method were evaluated during storage. The intensity ratings of these 15 sensory attributes at the beginning of storage (day zero) are presented in Table 1. Similar results for the attribute intensity ratings of coated peanuts were reported in other works (Grosso and Resurrección, 2002; Grosso et al., 2008). Significant differences $(\alpha=0.05)$ in the intensity ratings between samples were only found for the essential oil aroma attribute where the ratings were $27.0 \pm 1.20$ in $\mathrm{CP}-\mathrm{O}, 23.6 \pm 0.85$ in CP-L, $22.1 \pm 1.12$ in CP-R and zero (absent) in the samples without essential oil (CP and CP-BHT). Descriptive sensory attributes measured in a 150 $\mathrm{mm}$ unstructured line scale were also reported for other kinds of peanut products showing, in general, similar intensity ratings with respect to the sensory attributes in coated peanuts from this study (Mestrallet et al., 2004; Nepote et al., 2008, Riveros et al., 2009).

In general, the intensity ratings of sensory attributes did not change during storage time except for the intensity ratings of essential oil aroma and roasted peanutty attribute, which decreased, and the intensity ratings of oxidized and cardboard flavors, which increased during storage (Fig. 2). Volatile compounds that cause rancid odor and flavor are produced when the lipid oxidation process is in an advanced stage. These off-flavors are related to the oxidized attribute (Frankel, 2005). The oxidized intensity changes in coated peanut samples are presented in Fig. 2 (a). All products exhibited an increase in oxidized intensity ratings during storage. The initial intensities of this attribute in the peanut samples were between 5.9 (CP) and 6.3 (CP-L). Significant differences between samples in oxidized intensity were detected after day 28 where CP had a higher intensity rating. At the end of the storage period (112 days), the CP had the highest oxidized intensity rating (30.3) and CP-BHT had the lowest intensity rating (12.0). At this storage time, the coated peanut samples with essential oils showed oxidized intensity ratings $(\mathrm{CP}-\mathrm{O}=13.3, \mathrm{CP}-\mathrm{L}=13.5$ and $\mathrm{CP}-\mathrm{R}=16.1)$ between $\mathrm{CP}$ and $\mathrm{CP}-\mathrm{BHT}$. In a previous work fried-salted peanuts prepared with Runner kernels showed similar oxidized intensity ratings from 7 (day 0 ) to 31 (day 142) during storage at room temperature (Nepote et al., 2006c). Grosso and Resurreción (2002) found that coated peanuts had a lower oxidized intensity rating (49 at day 110 ) than roasted peanuts (61 at day 110 ) because the coating could decrease the oxygen uptake.

The cardboard flavor is also related to lipid oxidation (Frankel, 2005). This attribute showed a similar behavior to the oxidized flavor (Fig. 2-b). Significant differences between coated peanut samples were observed from day 28. At day 112 of storage, the intensity ratings of the cardboard attribute were 18.8 in CP, 14.2 in CP-R, 13.7 in CP-L, 13.4 in $\mathrm{CP}-\mathrm{O}$ and 12.1 in CP-BHT. The intensity ratings of cardboard flavor in samples added with essential oils (CP-R, CP-O and CP-L) were also between the intensities of CP and CP-BHT.

Roasted peanutty flavor is considered a positive sensory attribute in peanut products (Johnsen et al., 1988; Nepote et al., 2009). This flavor is related to a group of compounds named alquilpyrazines that are produced in the roasting process as a consequence of the reactions between the amine group of proteins and sugars. It was reported that a decrease in this sensory attribute is related to a decrease in the alquilpyrazine content (Bett and Boylston, 1992). It was also observed that the intensity ratings of roasted peanutty flavor decreased during storage in roasted peanut products (Grosso and Resurreccion 2002; Nepote et al., 2006a, b, c; Olmedo et al., 2008). In the present study, the intensity rating of roasted peanutty flavor decreased in all coated peanut samples throughout storage (Fig. 2-C). All samples showed the highest intensity in this attribute at the beginning of storage (day 0 ) when intensity ratings were between 53.1 (CP-O) and 51.9 (CP-R). At storage day 112, the intensities of roasted peanutty flavor were 47.9 in CP-L, 48.1 in $\mathrm{CP}, 48.2$ in CP-R, 48.8 in CP-O and 48.9 in CP-BHT. In a previous work roasted peanutty intensity ratings in fried-salted during storage decreased much more in regular Runner Peanuts with respect to high oleic peanuts (Nepote et al., 2006c). Friedsalted peanuts added with essential oils protected this product against losses of this attribute during storage (Olmedo et al., 2008).

CP-O had the highest initial intensity rating of essential oil aroma attribute (27.0) in comparison with CP-L (23.6) and CP-R (22.1). The highest decrease in the intensity ratings of this attribute with storage time was shown for CP-R (Fig. 2-d). These results indicate that the intensities of the oregano and laurel essences remain higher in the product than rosemary essence during storage.

\subsection{Correlation and regression analysis}

The correlation and regression analyses are presented in Table 3. Only variables of the samples that changed during storage were analyzed by correlations and regression analyses. These variables were the lipid oxidation indicators (PV and $A V)$ and essential oil aroma, roasted peanutty, oxidized and cardboard flavors.

PV, AV and oxidized and cardboard flavors showed a positive correlation higher than 0.7 . These values indicate that these variables increased their content or intensity rating during storage time. These same variables showed a negative correlation with essential oil aroma and roasted 
Table 3

Regression equations and $R^{2}$ for the dependent variables: peroxide (PV), $p$-anisidine (AV) values and sensory attributes in coated peanuts with and without addition of essential oils and BHT

\begin{tabular}{|c|c|c|c|c|c|}
\hline \multirow{2}{*}{$\begin{array}{l}\text { Dependent } \\
\text { Variable }\end{array}$} & \multirow{2}{*}{ Samples $^{a}$} & \multicolumn{2}{|c|}{ Regression coefficients ${ }^{b}$} & \multirow{2}{*}{ ANOVA $^{c}$} & \multirow{2}{*}{$\mathbf{R}^{2}$} \\
\hline & & $\beta_{0}$ & $\beta_{1}$ & & \\
\hline \multirow{3}{*}{ Essential Oil Aroma } & CP-L & 24.1480 & -0.0708 & $b$ & 0.85 \\
\hline & CP-O & 27.3200 & -0.1125 & $b$ & 0.95 \\
\hline & CP-R & 23.0340 & -0.1110 & $a$ & 0.87 \\
\hline \multirow{5}{*}{ Roasted Peanutty } & $\mathrm{CP}$ & 52.8378 & -0.0436 & a & 0.93 \\
\hline & CP-BHT & 52.7071 & -0.0331 & a & 0.82 \\
\hline & CP-L & 52.7958 & -0.0418 & a & 0.83 \\
\hline & CP-O & 53.3480 & -0.0414 & a & 0.91 \\
\hline & CP-R & 52.0698 & -0.0334 & a & 0.90 \\
\hline \multirow{5}{*}{ Oxidized } & $\mathrm{CP}$ & 5.4267 & 0.2237 & $d$ & 0.94 \\
\hline & CP-BHT & 5.0692 & 0.0486 & a & 0.73 \\
\hline & CP-L & 5.0805 & 0.0934 & c & 0.93 \\
\hline & CP-O & 5.5895 & 0.0715 & $b$ & 0.92 \\
\hline & CP-R & 5.6910 & 0.0707 & $b$ & 0.92 \\
\hline \multirow{5}{*}{ Cardboard } & $\mathrm{CP}$ & 10.0956 & 0.0717 & $d$ & 0.94 \\
\hline & CP-BHT & 9.4782 & 0.0206 & a & 0.86 \\
\hline & CP-L & 11.1589 & 0.0236 & a & 0.85 \\
\hline & CP-O & 9.4913 & 0.0301 & $b$ & 0.87 \\
\hline & CP-R & 9.5175 & 0.0389 & c & 0.95 \\
\hline \multirow{5}{*}{ AV } & $\mathrm{CP}$ & 0.6219 & 0.0355 & a & 0.85 \\
\hline & CP-BHT & 0.6034 & 0.0214 & $b$ & 0,84 \\
\hline & CP-L & 0.4441 & 0.0376 & a & 0.92 \\
\hline & CP-O & 0.3868 & 0.0399 & a & 0.88 \\
\hline & CP-R & 0.5061 & 0.0382 & a & 0.90 \\
\hline \multirow{5}{*}{ PV } & $\mathrm{CP}$ & 10.9699 & 0.5538 & c & 0.95 \\
\hline & CP-BHT & 8.6275 & 0.4179 & a & 0.93 \\
\hline & CP-L & 13.6047 & 0.4930 & $b$ & 0.93 \\
\hline & CP-O & 9.6242 & 0.5409 & c & 0.93 \\
\hline & CP-R & 11.2573 & 0.5363 & $c$ & 0.93 \\
\hline
\end{tabular}

${ }^{a} \mathrm{CP}$ : coated peanuts, CP-BHT: coated peanuts with BHT, CP-O: coated peanuts with oregano essential oil, CP-R: coated peanuts with rosemary essential oil and $C P-L$ : coated peanuts with laurel essential oil.

${ }^{\mathrm{b}}$ Regression equations: $Y=\beta_{0}+\beta_{1} X$, where $Y=$ dependent variable ( $P V, A V$ and sensory attributes) and $X=$ independent variable (days). ${ }^{c}$ The same letters in the column for every dependent variable mean that the slopes $\left(\beta_{1}\right)$ of regression equation are not significantly different at $\alpha=0.05$.

peanutty flavor. These last correlations were higher than -0.7 . This indicates that essential oil aroma and roasted peanutty flavor decreased during storage when the chemical and sensory variables related to lipid oxidation such as $P V, A V, C D$ and oxidized and cardboard flavors increased. Coated peanuts with the addition of essential oil (CP-O, CP-L and CP-R) showed a positive correlation between essential oil aroma and roasted peanut flavor. Bett and Boylston (1992) also detected that the cardboard flavor intensity in roasted peanuts had a linear increase across storage time while the roasted peanutty flavor intensity decreased as storage time increased. Nepote et al. (2006a,b) reported that chemical variables ( $P V, A V$ and $C D)$ and descriptive attributes (oxidized, cardboard and roasted peanutty flavors) were similar in roasted and fried-salted peanuts.

The linear regression equations of chemical and sensory variables (dependent variables) and 

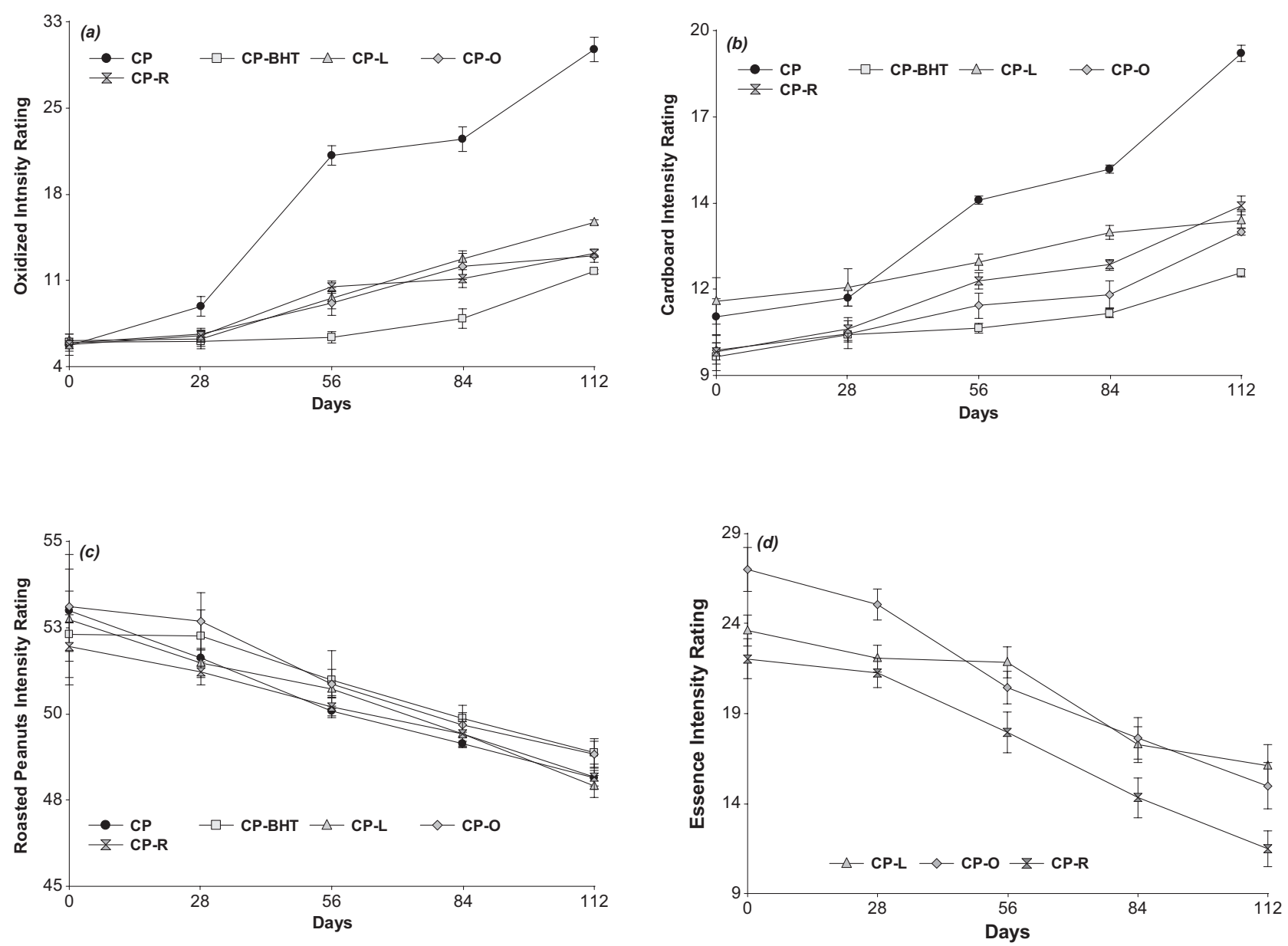

Figure 2

Intensity ratings of sensory attributes: a) oxidized, b) cardboard, c) roasted peanutty and d) essential oil aroma in coated peanuts (CP), coated peanuts with addition of essential oils of oregano (CP-O), rosemary (CP-R) and laurel (CP-L) and BHT (CP-BHT) during storage time.

storage time (independent variable) in coated peanut products are presented in Table 3 . The regression models for these variables showed an adjusted $R^{2}$ higher than 0.8 except for the variable oxidized flavor in CP-BHT, which was 0.73. Therefore, these variables can be considered good predictors for lipid oxidation changes in coated peanuts and these equations can be used to predict the chemical and sensory changes in this peanut product during storage. Significant differences in the regression equation slopes $\left(\beta_{1}\right)$ were found among samples for the dependent variables except for roasted peanutty (Table 2). These significant differences between slopes in some samples were evident depending on the antioxidant effect of oregano, laurel and rosemary essential oils in coated peanuts.

Grosso and Resurrección (2002) reported that roasted peanut samples with a value of 5 (neither like nor dislike) for overall acceptance on the 9 point hedonic scale can be considered as a level to decide if a peanut product is unacceptable for consumers. In addition, those authors found that cracker coated peanuts reached the 5 points in overall acceptance rating on the 9 point hedonic scale when the oxidized flavor rating was 27.4 in an unstructured lineal scale of $150 \mathrm{~mm}$. Using the regression equation obtained in this study and considering the intensity rating of 27.4 as a reference of shelf life for consumer acceptance for peanut products, this intensity rating should be reached after 96 days in CP, 235 days in CP-L, 299 days in CP-O, 301 days in CP-R and 451 days in $\mathrm{CP}-\mathrm{BHT}$. These predictions for shelf life considering oxidized flavor intensity in coated peanuts with and without the addition of essential oils indicate that rosemary, laurel and oregano essential oils have a protective effect against lipid oxidation in this peanut product prolonging its shelf life. However, these essential oils have been shown to be less effective than the synthetic antioxidant (BHT) but, most likely, these natural compounds will be considered better for food safety.

\section{CONCLUSIONS}

The results of the present work indicate that the addition of the essential oils of oregano, laurel and rosemary onto coated peanuts improves the stability of the product by preventing lipid oxidation and the 
development of rancid flavors. Therefore, these essential oils can be used as natural antioxidants in the case of coated peanuts. However, these natural antioxidants showed lower antioxidant effect on the stability of this product in comparison with BHT. Due to the fact that synthetic antioxidants such as butyl hydroxyl anisole (BHA), butyl hydroxyl toluene $(\mathrm{BHT})$ and propyl gallate $(\mathrm{PG})$ used in many foods for preventing rancidity still carry serious concerns for their potential health hazards, the present research renews interest in the use of naturally occurring antioxidants such as essential oils from aromatic plants.

This study also provides equations to estimate the shelf life of coated peanuts with the addition of natural and synthetic antioxidants by measuring the intensity ratings of some sensory attributes related to lipid oxidation, peroxide values or anisidine values.

\section{ACKNOWLEDGMENTS}

This work was supported by CONICET and SECYT-UNC.

\section{REFERENCES}

AOAC. 1980. Official Methods of Analysis of the AOAC (Edited by W. Horwitz). 13th Edition. Washington, DC: Ass. Off. Anal. Chem..

Benzie IFF. 1996. Lipid peroxidation: A review of causes, consequences, measurement and dietary influences. Int. J. Food Sci. Nutrit. 47, 233-244.

Bett KL and Boylston TD. 1992. Effect of storage on roasted peanut quality. In: Lipid Oxidation in Food (edited by A. J. St. Angelo). Pp 322-343. Washington, DC, USA: ACS Symposium Series 500, Am. Chem.Soc.

Frankel EN. 2005. Lipid Oxidation, 2nd Edition. Pp 1-470. Bridgewater, England: The Oily Press.

Frutos MJ and Hernandez-Herrero JA. 2005. Effects of rosemary extract (Rosmarinus officinalis) on the stability of bread with an oil, garlic and parsley dressing. LWT, 38, 651-655.

Grosso NR and Guzman CA. 1995. Chemical composition of aboriginal peanut $(A$. hypogaea) seeds from Peru. J. Agric. Food Chem. 43, 102-105.

Grosso NR and Resurreccion AVA. 2002. Predicting consumer acceptance ratings of cracker-coated and roasted peanuts from descriptive analysis and hexanal measurements. J. Food Sci, 67, 1530-1537.

Grosso NR, Lucini El, Lopez A and Guzmán CA. 1999. Chemical composition of aboriginal peanut (Arachis hypogaea L.) seeds from Uruguay. Grasas Aceites 50, 203-207.

Grosso NR, Resurreccion AVA, Walker GM and Chinnan MJ. 2008. Sensory profiles and hexanal content of cracker-coated and roasted peanuts stored under different temperatures. J. Food Process. Pres. 32, $1-23$

Grosso NR, Zygadlo JA, Burroni L and Guzmán CA. 1997. Fatty acid, sterol and proximate compositions of peanut species (Arachis L.) seeds from Bolivia and Argentina. Grasas Aceites 48, 219-225.

IUPAC. 1987. Method Number 2.504. Determination of the $p$-anisidine value. In: Standard Methods for the Analysis of Oils, Fats and Derivatives (Edited by
C. Paquot \& A. Hautfenne). $7^{\text {th }}$ Edition. Oxford, UK: Blackwell Scientific Publications.

Johnsen PB, Civille GV, Vercellotti JR, Sanders TH and Dus CA. 1988. Development of a lexicon for the description of peanut flavour. J. Sens. Stud. 3, 9-17.

Kulisic T, Radonic A, Katalinic V and Milos M. 2004. Use of different methods for testing antioxidative activity of oregano essential oil. Food Chem. 85, 633-640.

Meilgaard M, Civille GV and Carr BT. 1991. Sensory Evaluation Techniques. 2nd Edition. Pp 135-183. Boca Raton, Florida: CRC Press Inc.

Mestrallet MG, Carnacini L, Días MJ, Nepote V, Ryan L, Conci S and Grosso NR. 2004. Honey roasted peanuts and roasted peanuts from Argentina. sensorial and chemical analysis. Grasas Aceites 55, 401-408.

Nepote V, Grosso NR and Guzmán CA. 2002. Extraction of antioxidant components from peanut skins. Grasas Aceites 53, 391-395.

Nepote V, Mestrallet MG and Grosso NR. 2006c. Oxidative stability in fried-salted peanuts elaborated with higholeic and regular peanuts from Argentina. Int. J. Food Sci. Tech. 41, 900-909.

Nepote V, Mestrallet MG, Accietto R, Galizzi M and Grosso NR. 2006b. Chemical and sensory stability of roasted high-oleic peanuts from Argentina. J.Sci. Food Agric. 86, 944-952.

Nepote V, Mestrallet MG, Olmedo RH, Ryan LC, Conci $S$ and Grosso NR. 2008. Chemical composition and sensory analysis of roasted peanuts coated with prickly pear and algarrobo pod syrups. Grasas Aceites 59, 174-181.

Nepote V, Mestrallet MG, Ryan L, Conci S and Grosso NR. 2006a. Sensorial and chemical changes in honey roasted peanuts and roasted peanuts stored under different temperatures. J. Sci. Food Agric. 86, 10571063.

Nepote V, Olmedo RH, Mestrallet MG and Grosso NR. 2009. A Study of the Relationships among Consumer Acceptance, Oxidation Chemical Indicators and Sensory Attributes in High-Oleic and Normal Peanuts. J. Food Sci. 74, 1-8.

Olmedo R, Nepote V, Mestrallet M and Grosso NR. 2008. Effect of the essential oil addition on the oxidative stability of fried-salted peanuts. Int. J. Food Sci. Tech. 43, 1935-1944.

Plemmons LE and Resurreccion AVA. 1998. A warm-up sample improves reliability of responses in descriptive analysis. Journal of Sensory Studies, 13, 359-376.

Pokorny J. 1991. Natural antioxidant for food use. Trends Food Sci. Tech. 9, 223-227.

Riveros C, Mestrallet MG, Nepote V and Grosso NR. 2009. Chemical composition and sensory analysis of peanut pastes elaborated with high-oleic and regular peanuts from Argentina. Grasas Aceites 60, 388-395.

Sacchetti G, Maietti S, Muzzoli M, Scaglianti M, Manfredini S, Radice M and Bruni R. 2005. Comparative evaluation of 11 essential oils of different origin as functional antioxidants, antiradicals and antimicrobials in foods. Food Chem. 91, 621-632.

Sokal RR and Rohlf FJ. 1994. Biometry, 3rd edition. San Francisco: W.H. Freeman.

Zygadlo JA, Lamarque AL, Grosso NR and Maestri DM. 1995. Empleo de aceites esenciales como antioxidantes naturales. Grasas Aceites, 46, 285-288.

Recibido: 6/5/11 Aceptado: 15/7/11 